\title{
ENTREVISTA
}

\section{PRODUÇÃO CULTURAL E AUTORREPRESENTAÇÃO \\ Léo Lima, educador, fotógrafo e trabalhador cultural (Jacarezinho-RJ, UFRJ)}

\author{
Paula Ferreira da Silva ${ }^{1}$
}

\begin{abstract}
Resumo: Trata-se de uma entrevista com um jovem produtor de cultura da periferia do Rio de Janeiro - RJ idealizador e criador do Coletivo Cafuné na Laje². Atua em prol do fortalecimento de memórias locais, empoderamento coletivo a partir de atividades culturais e media a criação de filmes feitos por crianças. A iniciativa contribui com estratégias de mobilização local e investimento de uma possível transformação social a partir do seu olhar sobre a realidade que vive. Ao problematizar a realidade e fomentar cultura, sobretudo na Favela do Jacarezinho, experimenta metodologias que possibilita criar um modo próprio de fazer. O objetivo da entrevista foi perceber mais profundamente e compartilhar como a proposta foi idealizada, os caminhos trilhados, desafios enfrentados, estratégias desenvolvidas, conquistas, participações em editais públicos, visão sobre políticas culturais ditas “afirmativas", e também, discorrer sobre a atuação de um produtor cultural morador de periferia e que potencializa e expande suas ações para outros "centros".
\end{abstract}

Palavras-Chave:Coletivo Cultural. Protagonismo. Produção Cultural Periférica.

\section{Apresentação}

Coletivos culturais realizam ações significativas e substanciais de fortalecimento de memórias locais e empoderamento coletivo, com isso, promovem o desenvolvimento de "sistemas comunitários". As proposições incluem reflexões políticas, atividades artísticas, oficinas de criação para moradores e, embora ainda invisibilizados, a partir de relações em rede, online ou offline, buscam e encontram espaços de atuação e são sempre convidados a mostrar suas produções e dialogarem com diversos públicos.

\footnotetext{
${ }^{1}$ Pedagoga, mestranda em Crítica Cultural pela Universidade do Estado da Bahia (UNEB/Campus II). Alagoinhas - Bahia. Endereço eletrônico: paulamorenaproducoes@gmail.com.

${ }^{2}$ Endereço da página do coletivo no Facebook e no youtube: https://www.facebook.com/cafunenalaje/?fref=ts | https://www.youtube.com/watch?v=3mpqcTHabRI
} 
Os modos de fazer de grupos periféricos ${ }^{3}$, graças a "explosão" de coletivos artísticos da periferia, começam a ser vistos como potências criativas, por isso, são convidados a compartilharem suas ações para outros grupos independentes ou organizações institucionalizadas. Essa emancipação provoca novas relações em rede e inspiram outras experiências a desabrocharem, pois, na medida em que criam ações e se expandem, ganham força e estimulam o surgimento de novos grupos potentes. Além de convidados para debates, também propõem pautas e atividades mesmo cientes das ideias hegemônicas que permeiam o imaginário acerca da noção de sujeito e da arte periférica. Como grupos mobilizados politicamente, "atropelam" as adversidades, realizam suas produções e não deixam de lutar para ocupar espaços que respeitem seus modos autônomos de realizar e refletir.

Essa entrevista foi realizada com um produtor cultural periférico no que tange produções independentes realizadas na periferia e/ou em outros espaços, cuja atuação é romper com lógicas hegemônicas de produção técnica e oferta de cultura. Acredita-se que a experiência está relacionada com novos modos de fazer, saberes autônomos e metodologias que podem resultar em experiências exitosas, também, no campo da Arte-Educação. O projeto cultural desenvolvido é o coletivo Cafuné na Laje que, além de outras atividades, realiza o cinema brincante com crianças a partir de uma construção coletiva, respeitando os desejos delas na enunciação de ideias a serem abordadas no produto fílmico e na atividade prática de construir roteiro, filmar e encenar. Entre outras coisas, essa entrevista traz uma narrativa "alternativa" de quem ainda está em crescimento intelectual, o que contrapõem narrativas “acadêmicas", mas podem ser tão inspiradoras quanto.

O diálogo se deu com um jovem ativista, trabalhador cultural, (conforme ele deixa claro na entrevista), que utiliza seu olhar comunitário e solidário para compartilhar experiências e aprender a partir da troca coletiva. O entrevistado é Léo Lima, morador nascido e criado na Favela do Jacarezinho,

\footnotetext{
${ }^{3}$ Fala-se aqui de vários grupos, não apenas os oriundos de periferia. Com problematizações a partir de leituras das disciplinas do Mestrado em Pós-Crítica surgiram questões a cerca da forma como o termo "periférico" é empregado. Com qual objetivo/sentido? É uma identidade, uma outra subjetividade, uma autoatribuição? A que esse conceito remete, valoriza e/ou desvaloriza? São algumas questões do projeto de pesquisa da entrevistadora e de sua experiência pessoal.
} 
uma das maiores favelas localizadas na zona norte do município do Rio de Janeiro - RJ, fotógrafo, educador, estudante do curso de Pedagogia da Universidade Federal do Rio de Janeiro - UFRJ e idealizador do coletivo Cafuné na Laje. Segundo ele, o seu percurso foi sendo tecido a partir de "pessoas inspiradoras".

Trabalhador cultural é aquele que busca incentivar mudanças subjetivas e da realidade ao contribuir com a descolonização do imaginário sobre seu contexto local, a periferia/favela. Sua atuação se dá a partir do seu olhar, de "dentro", ou seja, do "centro" da realidade que vive. Utiliza a criatividade como solução para driblar as adversidades do agir "independente" e traz novas ideias para o cenário da cultura, porém, como qualquer grupo/coletivo idealizado/criado, este não seria diferente, possui suas peculiaridades, também, contradições.

PFS: Para início de conversa, com o intuito de melhor apresentá-lo, acredito ser importante conhecermos o seu percurso pessoal, profissional e acadêmico. Pode discorrer um pouco sobre ele?

LL: Eu sou morador da Favela do Jacarezinho no Rio de Janeiro, nascido e criado neste lugar. Tenho 28 anos, sou pai da Malu, botafoguense e integrante dos Coletivos "Favela em Foco", "Imagens do Povo" e "Cafuné na Laje". Nunca fui de me interessar por muita coisa, gostava das coisas que não faziam barulho, tipo desenhar. Em 2007 conheci a fotografia através das imagens de João Roberto Ripper. Ele foi quem me apresentou a comunicação como sendo um direito humano fundamental, que fotografia é comunicação e que todas as pessoas têm direito de buscar a informação que desejam saber e de usar qualquer meio pra divulgá-la. Ele é um fotógrafo do bem querer que, de alguma forma, me mostrou que mais vale uma boa história do que uma boa fotografia. E, quando aliamos essas duas coisas, fazemos valer o papel do fotodocumentarista de querer bem ao fotógrafo ou ao que sua fotografia está a serviço. Ripper é um fotógrafo que luta pelo direito de crédito e pela tabela de preços mínimos aos profissionais da fotografia e documenta ribeirinhos, quilombolas, indígenas. As palavras de Fabio Caffé e Rovena Rosa, colegas que além de terem sido meus primeiros professores no curso de fotografia, com a linha de trabalho e atuação em sala e em campo muito similar ao do Ripper de 
apresentar uma fotografia solidária, eles me influenciaram muito, pois, para mim a fotografia era a de paparazzi. Era o que chegava para mim como verdade. De certa forma ter conhecido essas pessoas fizeram com que eu quebrasse meus próprios estereótipos e buscasse outras verdades sobre o meu ser favelado, meu ser fotógrafo, e claro, as escolhas que fiz até hoje se devem muito a essas figuras que conheci ainda no “Observatório de Favelas”. Daí fui para o curso de fotografia, consegui expor meus trabalhos individualmente e coletivamente. Eu cresci entre injustiças, violências e utopias por uma favela melhor, e como fotógrafo, aos meus olhos pulsa imagens que eu possa contribuir com um olhar harmônico das favelas e de suas lutas. Já fui mais engajado nas documentações sobre remoções no Rio de Janeiro devido aos megaeventos e que só afetaram e afetam as favelas. Hoje, concentro minha fotografia no que chamo de "fotografia social" e faço festinhas nos becos e lajes daqui da favela e não cobro por isso. Acho justo compartilhar o conhecimento e a técnica que adquiri com anos de fotografia. Cobro apenas pelas revelações das fotos. Em 2013 entrei (depois de 7 anos de ensino médio concluído) para UFRJ no curso de pedagogia. Quero "influenciar" a Universidade com meu olhar comunitário, compartilhado e solidário. Como também quero aprender com a Universidade. Quero aproveitar as brechas, conseguir as parcerias necessárias para que minhas ideias sejam fluxo, sejam mar, que vá e volte! Não quero ser dono de nada, muito menos patrão - quanto menos, melhor - acho difícil romper com o capitalismo sendo pobre, é difícil falar isso para o pobre, logo, vejo que o mais importante é se proteger das violências dessa mesma sociedade capitalista e fazer com que a cada passo, como na utopia de Galeano, seja mais um passo para uma sociedade justa, onde a solidariedade seja o mote principal para os desafios da educação.

PFS: O que fazem os Coletivos Favela em Foco Imagens do Povo?

LL: O Favela em Foco é um coletivo multimídia formado por fotógrafos oriundos de espaços populares que se propõem a atuar em favelas cariocas abordando questões relacionadas a esses espaços com o objetivo fundamental de descolonizar o olhar estereotipado e marginalizado sobre as favelas, muito feito pelas mídias corporativas atualmente. O Imagens do Povo desenvolve ações nas esferas da educação, comunicação e arte com objetivo de 
democratizar o acesso à linguagem fotográfica e apresentar a fotografia como técnica de expressão e visão autoral da sociedade. O foco crítico consiste em formar e promover documentaristas fotográficos, potenciais multiplicadores do saber adquirido e capazes de desenvolver trabalhos autorais de registro de espaços populares, valorizando as histórias e as práticas culturais de suas comunidades, além de estimular o fortalecimento de vínculos identitários a partir do uso da linguagem fotográfica, que se torna instrumento de acesso e mapeamento de diferentes expressões culturais e sociais dos territórios onde residem para ampliar as possibilidades de difusão de novas imagens destes locais.

PFS: No seu percurso enquanto fotógrafo quais eventos participou mostrando seu ponto de vista artístico?

LL: Eu não lembro muito de minhas premiações, não me ligo nessas coisas. Nem guardo isso nem nada (sei que dou mole), mas do que lembro tirei um $3^{\circ}$ lugar num concurso fotográfico de um jornal que, em 2010, me possibilitou comprar um computador legal pra tratar fotos. Fui finalista no prêmio "Photo Prix" da aliança francesa em 2012. Participei de coletivas junto ao Imagens do Povo como "Desde junho nas ruas do Rio" sobre as manifestações de 2013, como também “Folia de Imagens" no mesmo ano, sobre as manifestações carnavalescas no Rio de Janeiro, e em Montevidéu também. Com "Favela em Foco" fizemos exposições nas favelas do Alemão, Jacarezinho, Manguinhos, Bandeira 2, Vila Autódromo, Chapadão, Providência e Honório Gurgel. Meu trabalho se pauta no retorno, como me engajo em muitas situações, faço questão de retorná-las às pessoas. Só participei de uma exposição individual chamada "Confiança" que é um trabalho que desenvolvo sobre cotidiano de imagens que demonstrem, nos olhares dos personagens, a confiança que também tenho neles. É uma troca!

PFS: Antes de cursar Pedagogia você teve alguma experiência de docência ou em projetos que possa ter ajudado na formulação de ideias para o coletivo?

LL: Sim. Fui convidado pelas artistas Tatiana Altberg e Joana Mazza em 2010 a acompanhar o arte-educador Fagner França na prática e pedagogização da técnica pinhole. Aceitei o desafio e formamos uma parceria 
muito rica de quase 4 anos a frente desse projeto. Foi nesse período que tomei gosto pela educação, pois a própria Tatiana me influenciava a estudar e dizia que eu tinha uma "pegada" para coisa devido meu modo de lidar com as diferenças porque sempre fui muito sereno. Com as crianças aprendi que se elas não me entenderam, o problema estava na forma como lidava com elas. Depois conheci as ideias de Paulo Freire em rodas de conversa, de José Pacheco, Rubem Alves, Mario Sergio Cortella e Anísio Teixeira e fui aprendendo e convivendo com as crianças. Então decidi prestar o vestibular e tentar a pedagogia. Entrei para UFRJ sabendo do que queria, mas daí me vi em outros desafios ainda maiores, outras buscas. Nesse meio tempo, o cinema me escolheu e parece que ele e a educação serão meu foco.

PFS: Você se considera um produtor cultural periférico?

LL: Periférico não. Interpreto o periférico como se estivesse à margem. Esse não é o meu caso. Acredito ser um trabalhador cultural. Que trabalha, às vezes sem receber "um puto" pela cultura brasileira. Além de trabalhar "para", alimento cultura com outras pessoas. No Jacarezinho criando filmes, contribuindo com a criação, com a identidade dos moradores daqui. Ajudo na quebra do estereótipo sobre a favela. Em resumo, diria que sou um trabalhador cultural do mundo e tenho o Jacarezinho como o centro do mundo. Não me considero à margem é o que quero dizer.

PFS: O saber do produtor cultural periférico mesmo que construído de forma autônoma e autodidata, contribui para ampliação de ideias no cenário cultural para além da periferia?

LL: Acho importante todo e qualquer tipo de ação que envolva a cultura. Acredito que a potência está em ter coragem e fazer valer uma ideia de que aquela cultura apresentada, seja num filme, num texto ou numa fotografia é relevante para cultura como um todo. Claro que, no meu caso, especialmente para favela, pois as pessoas precisam se reconhecer, mais do que sentem-se representadas, elas precisam se autorrepresentarem. Representatividade conta muito. A inovação se dá num campo mais geral né, pois é um tipo de "produto" que não é consumido diariamente. A favela ainda é um "produto" a ser consumido, o que vemos hoje em dia nas mídias corporativas são favelas pasteurizadas, feitas por roteiristas que não são favelados. Podem ter 
proximidade com elas, mas não vivem as favelas. É diferente um favelado falar sobre a favela e um burguês falar sobre ela. As visões, mesmo que haja uma pesquisa antropológica, serão visões interpretativas que, ao mesmo ponto que não podem ser "demonizadas", não podem ser ignoradas as tensões na sociedade que um roteirista, fotógrafo, cineasta vivente da favela causa quando surge no cenário. "Nós" levamos paro o cenário nossas emoções, as histórias das crianças brincando em meio aos buracos das calçadas, no emaranhado dos fios, nas risadas e banhos, muitas vezes com fuzis atravessados em nossos peitos, diariamente. Isso já diz qual é a potência do novo cenário, pois sobrevivemos e estamos reinventando as formas de fazer cultura. Dessa vez, de dentro para dentro primeiro, depois, para fora.

PFS: Quais os desafios enfrentados para realizar as ações idealizadas pelo coletivo?

LL: Eu diria que, inicialmente, dinheiro. Ou temos dinheiro de edital público para fazer ou precisamos de dinheiro conseguido por outros meios. Esses outros meios nos fazem ficar longe do que realmente queremos fazer. Tá mais do que na hora do governo criar uma bolsa cultura que seja um projeto de lei e não de governo. Isso, onde as pessoas sejam escolhidas a partir de um critério a ser discutido junto, não o da disputa dos editais e, que possa ter um valor considerável (mensalmente e durante anos) para que esse agente possa atuar em prol da cultura sem precisar parar o trabalho que está sendo feito, porque não há mais verba, porque mudou o governo ou porque as contas em casa apertaram. Tá mais do que na hora de reconhecer que nossa juventude, tão potente, merece respeito. Talvez um desafio maior nem seja tanto o dinheiro, e sim, convencer o governo que não queremos migalhas. Precisamos pensar um projeto cultural a longo prazo, com renovações, com interseções entre escolas e universidades. Com a rua na Universidade e a Universidade na rua e com a escola como um espaço dos bairros que seja aberta, sem grades e afetiva. É tudo desafio.

PFS: O Cafuné na Laje criou alianças em pouco tempo de experiência com outros coletivos, também, com organizações?

LL: Com várias. Somos sempre convidados por outros locais e inclui: universidades, bibliotecas públicas, escolas públicas, entidades privadas como 
o SESC. Geralmente pedem para debatermos sobre a metodologia utilizada no Cafuné na Laje. Como fazemos os filmes e quais os processos trabalhados. Somos convidados também a exibir nossos filmes e é sempre uma troca importante para democracia, considero, e pela importância de ouvir, aprender com o outro e influenciar quem te ouve.

PFS: Conte-nos sobre o coletivo.

LL: O primeiro cafuné começou na laje da minha mãe. Enquanto conversava com Aline Santos, minha falecida companheira e mãe de minha filha, percebemos o cafuné entre dois gatos e ao vermos aquele carinho sincero, sorrindo, falamos: - "Ê cafuné na laje gostoso". Nessa ocasião ouvíamos a música "A Cada Vento" do rapper Emicida e embebidos dessa influência de sensações pegamos nossa câmera filmadora e começamos a filmá-los de perto, nos olhos, percebendo-os ainda mais, através das lentes. Acompanhar o cotidiano dos gatos e das crianças nas lajes vizinhas foi o ponto de partida para pensar a vida na favela como dispositivo para o cinema, sobretudo, para a educação. Fomos muito bem acolhidos pelo Jacarezinho e seus moradores. No Azul, localidade mais alta do morro, estão as crianças que dão o sentido às nossas ações. O desejo aliado ao brincar, que sempre nos faz pensar a arte e a educação a partir da vivência no lugar, inspiração fundamental para que as peças fílmicas continuem a brotar. Disso surgiu o cinema brincante que é o encontro entre diversas formas de estímulos e dinâmicas que envolvam brincadeiras presentes no cotidiano, fazendo desses dispositivos, métodos para criação de roteiros de filmes. Mesmo não acontecendo com regularidade por dispor de pouca estrutura e recursos, a oficina de cinema brincante, em três anos de atividades, conseguiu organizar pelo menos dez encontros com crianças e adolescentes do Jacarezinho. No filmar é que o aprendizado se dá, entendendo de maneira horizontal e orgânica, todos os participantes como produtores, diretores e atores sociais, e, principalmente, como protagonistas na construção de uma obra coletiva. As temáticas têm como fio condutor uma experiência audiovisual a partir da descoberta empírica, estética e de autorrepresentação que abordem questões que envolvem a valorização da vida na favela. Durante os encontros as crianças usam sua criatividade para dar origem a diversos personagens que podem ser bonecos pintados, em papel, com 
lápis de cor ou personagens interpretados pelos próprios moradores, inclusive adultos que nunca haviam atuado na vida. As narrativas também são diversas, vão desde uma brincadeira em beber um gole de leite fermentado escondido que deu origem ao curta "Lactobacilos Vivos" à uma reflexão sobre a elitização nos estádios de futebol durante a Copa do Mundo 2014 no Brasil, retratado no curta "Eu não vou pra Copa". Com tecnologias acessíveis como câmeras fotográficas e celulares, facilitamos o aprendizado das crianças, empoderandoas para a criação e publicação de curtas em plataformas de compartilhamentos de vídeos na internet. Esses filmes também são lançados em cineclubes realizados pela Cafuné na Laje em lajes do Morro Azul, ou lajes cedidas por algum morador parceiro ou em algum local público (quadras, praças e ruas). Essa ação fortalece o protagonismo, reconhecimento e a valorização das pessoas envolvidas dentro da comunidade. Então, esse Coletivo é uma iniciativa de arte e educação independente, voltada a moradores de espaços populares, (favelas, quilombos, assentamentos, áreas ribeirinhas e outros) e para crianças, adolescentes e professores. Atuamos através da criação de eventos culturais, oficinas de fotografia, audiovisual e exibição de filmes através de cineclubes. Com esse trabalho, visamos contribuir diretamente com a reflexão sobre a educação, o acesso às artes e novas mídias com ações voltadas aos moradores para utilização dessas ferramentas em ambientes educacionais formais ou informais. Cerca de 40 crianças e adolescentes se beneficiam dessa iniciativa de modo direto, no que diz respeito às oficinas de cinema brincante. Além disso, os espectadores nos cineclubes também são beneficiados dessa ação. Cerca de 500 pessoas já acompanharam as exibições que fizemos nas lajes e na quadra do Azul. Temos atualmente mais de 2600 assinantes em nossa página no Facebook. Nosso público prioritário é a juventude e os moradores do Jacaré de uma maneira geral, que são os protagonistas de nossas ações. Além deles, estudantes, professores, pesquisadores e amantes do cinema e da vida são parte dos que nos motivam a agir.

PFS: A partir das experiências e reflexões sobre o processo desenvolvido pelo coletivo até o momento, você considera que as ações têm um desdobramento rizomático? Por quê? Como se dá? 
LL: Sim, até porque a educação está para nós como um processo inacabável, atemporal, possível e viável de ser realizado em qualquer ambiente desde que sejam respeitados todos os desejos, histórias, medos, anseios, acasos e incertezas existentes em todos os indivíduos e processos sociais. Mais do que um coletivo, o Cafuné na Laje é uma ideia aberta para ser seguida ou reinventada por qualquer um. As experiências que tivemos até hoje foram de valorização dos processos, mais do que os resultados e isso não conseguimos mensurar em termos quantitativos, mas qualitativos e percebemos nos olhares dos amigos e amigas que estamos nos entendendo, observando nossos limites e onde não somos tão produtivos, assim como cada criança em processo conosco na criação dos curtas.

PFS: Além dos curtas com crianças quais outras atividades o coletivo realiza?

LL: Em 2013 e 2014 produzimos o filme "Favela que me viu crescer", um documentário que retrata a vida de quatro moradores: Tia Dorinha, Vó Chiquinha, Tião do Azul e Mais Preto. A partir dos seus relatos e cotidianos, o filme entrelaça suas narrativas e relações de afeto construídas ao longo tempo com o Jacarezinho, lugar que viram crescer e cresceram juntos. O filme foi realizado com financiamento do Ministério da Cultura pelo edital Curta Afirmativo destinado a produtores negros. Com o recurso, adquirimos parte do equipamento que pretendemos utilizar na continuação das oficinas. O lançamento do filme foi em 2015, um evento realizado na Quadra do Azul que é a parte mais alta da Favela pela própria Cafuné na Laje, em parceria com moradores e comerciantes do local, o Cinemão que disponibilizou sua infraestrutura para exibir o filme e o Coletivo Norte Comum também participou. Além disso, desenvolvemos desde 2015, o "Encontro das Lajes", evento que reúne artistas da cidade para uma troca de ideia sobre arte, cultura e educação, onde compartilhamos trabalhos desenvolvidos por nós e pelos convidados. No encontro, já contamos com a participação do cantor Criolo e da cantora Janine Mathias. Também já realizamos eventos como roda de samba e forró como uma das fontes de renda do Coletivo com a venda de bebidas e comidas. 
PFS: Você escreveu o argumento para o Documentário "Favela que me viu Crescer", primeiro documentário do coletivo e financiado por edital público, como surgiu a ideia?

LL: Desde que botei na cabeça que tínhamos que fazer um filme sobre o Jacarezinho sabia que precisava da ajuda dos amigos e das amigas. Lembro que o argumento foi feito baseado no pouco de história da favela que eu havia apurado até 2012. Num esquema que só eu, enquanto morador da localidade, conseguiria compreender já que não tinha um método de pesquisa específico, percebi que o Samba, o futebol de várzea, a imigração nordestina e o sincretismo de Tia Dorinha eram os temas mais latentes aos meus ouvidos quando se ouvia falar de "Azul", sem contar as fábricas industriais do entorno e a Igreja do Padre Nelson tão importante quanto o que foi citado. A preocupação inicial era criar um argumento para um filme onde os moradores se sentissem representados na telona. E foi aí que percebi que o argumento do filme não seria sobre o Jacarezinho, pois dar conta do que é a favela seria um grande desafio e daí considerei que não poderia ser já no primeiro argumento. Decidi que o argumento do filme seria sobre o Morro Azul como parte da cultura do Jacarezinho, buscando seus personagens e histórias que se misturavam com todo o morro. Pois eram, coincidentemente, de lá onde os personagens moravam ou viveram momentos que contribuíram para a construção da história da favela. Assim, listei perfis de pessoas que poderiam ser entrevistadas e passei para a Paula Morena, que passou para JV Santos, que voltou pra mim, passou na mão de Aline Santos, e foi como os sambistas quando fazem suas músicas que botam uma cerveja na mesa, escreve de um lado, passa pro outro, um faz o refrão e assim vai. Tínhamos um argumento forte, utópico e necessário. Paula Morena, como diretora artística do filme, esteve a frente comigo o tempo inteiro desse projeto e firmamos uma bela dupla de trabalho, onde obtive muitos aprendizados, inclusive sobre minha escrita.

PFS: Como se deu a recepção do documentário?

LL: Não consigo mensurar o impacto que o filme teve nos lugares. O que posso dizer é que as pessoas gostam muito do filme e dizem que não sabiam nem que o Jacarezinho era um morro e que tem uma história muito rica ainda para se buscar. Essa percepção era o que imaginávamos e, por isso, também que 
o filme foi realizado. No Jacarezinho, das vezes que exibimos, o que vimos foi uma emoção sem tamanho e a quadra lotada para ver o filme! Personagens agradecendo, nos beijando, pessoas felizes, crianças felizes, tudo foi muito mágico, lindo e temos registro fotográfico disso. Nas bibliotecas, eventos e outras favelas, as emoções foram mais contidas, mas sempre há choro. É um filme particularmente lindo! Lembro que ele ainda não estreou na internet e, que ainda não iniciamos nossa distribuição caseira.

PFS: Vocês refletem sobre mudanças em políticas culturais que favoreçam e incluam a participação de coletivos no circuito da produção cultural da cidade?

LL: Acho interessante as propostas dos editais afirmativos, micro editais e de menor exigência porque são menos problemáticos de prestar conta. Inclusive foi por intermédio do edital curta afirmativo que conseguimos realizar nosso primeiro documentário. A verba ajudou a comprar equipamentos e estruturou minimamente nosso sonho. Mas como disse antes, é preciso criar políticas públicas e não políticas de governo que se esgotem com mais um novo eleito. $\mathrm{O}$ incentivo da produção cultural precisa se estender inclusive para aqueles garotos, meninas que nem sabem ainda o significado da palavra, mas já agem. Precisam de investimento. É necessário uma bolsa cultura que dure anos até que esse adolescente consiga trilhar seus caminhos. Isso não salva a vida de alguém, mas oportuniza. Apesar das ações afirmativas serem interessantes, continuamos num esquema de disputa entre si, acho isso horrível. Ganhar de alguém! Se faz necessário cada vez mais iniciativas de integração e não de subtração.

PFS: Atualmente, estão participando de algum edital ou projeto via políticas públicas?

LL: Sim. O Ações Locais que é uma iniciativa da prefeitura do Rio de Janeiro, contraditoriamente, a que mais removeu gente pobre, preta e favelada da história. Temos que fazer, mas que fique bem claro que esse trabalho já fazemos sem ter grana. Enfim, essa ação tem sua importância, porém mais uma vez nos colocou em disputa com outros colegas e coletivos do próprio Jacarezinho. Estamos em conversa para burlar isso e fazer com que todos que entraram, de alguma forma, usufruam também, como protagonistas. Para o 
projeto, pensamos em uma oficina de cinema brincante, onde teremos aulas durante 8 meses em uma localidade daqui do Jacarezinho com atividades voltadas ao cinema para crianças de até 16 anos. Recebemos uma bolsa de R\$700,00 por mês para trabalhar e as aulas serão estímulos brincantes para a construção de roteiros e peças ficcionais, tendo as histórias dos moradores do Jacarezinho como ponto de fuga para a criação. Para isso, estamos transcrevendo todas as pesquisas que fizemos e fazemos com os moradores para que pensemos o cinema como um todo, até onde ele pode ir, contribuir, virar exposição, museu, teatro, pesquisa e etc. Ainda não fomos contemplados, estamos na fase de habilitação. É um edital de R\$25 mil. É muito pouco e acaba que a grana paga a bolsa, lanche das crianças, mas coloca a gente por mais um ano em atividade com apenas $\mathrm{R} \$ 700,00$ mensais na conta, que é pouco, porém é melhor que nada. Entretanto, não queremos migalhas, sabemos onde estamos pisando com esse edital, ninguém está salvando nossas vidas muito menos dando as melhores condições para trabalhar. Acredito que a liberdade se conquista, o financiamento coletivo mais me agrada do que os editais que nos domesticam.

PFS: Deseja colocar alguma coisa, comentar algum ponto que não foi abordado?

LL: Sim. Nosso diálogo a partir do Coletivo é sempre com os moradores. No início, em 2013, éramos sempre mais cautelosos em levar a câmera para rua e filmar. Com o tempo esse diálogo começou a se dar de outra forma, mais na presença do que no aviso de que algo iria acontecer. Com a gravação do documentário "Favela que me viu Crescer" a grande maioria dos moradores do Morro Azul já se sentia mais à vontade conosco e percebemos nas palavras e nos olhares, a confiança de todos. A UPP - Unidade de Polícia Pacificadora em nenhum momento mediou nossas ações e jamais se mostrou interessada em fazê-lo de nenhuma forma. Vale ressaltar, mais uma vez, que, com nossa iniciativa, não estamos tirando ninguém do tráfico de drogas ou da possibilidade de trabalharem como policiais e, principalmente, não estamos profissionalizando nenhuma das crianças. Estamos apresentando a todos, uma possibilidade de estar vivo, de construir um projeto junto e de colocar à disposição uma ferramenta de transformação sociocultural, de maneira 
gratuita e afetiva. Queremos estar próximos deles e aprender junto. Acreditamos que são os participantes dessa ação que dirão, no futuro, para que serviu o Coletivo Cafuné na Laje, não, nós. 